\title{
Case of Teachers' Communicative Competence Development Within the System of Methodological Work in the Context of Preschool Educational Establishments
}

\author{
Victoria Sergeevna Vasilyeva ${ }^{1}{ }^{*}$, Elena Yurievna Nikitina ${ }^{1}$ \\ ${ }^{1}$ South-Ural State Humanitarian Pedagogical University, Lenin Avenue, 69, Chelyabinsk, 454080, Russia \\ *Corresponding author E-mail: vasilyeva.v.s@mail.ru
}

\begin{abstract}
The urgency of the problem of communicative competence development of preschool teachers is caused by the need for constant improvement of pedagogical approaches, methods and technologies. The development of teachers' skills in the process of continuing professional activities is crucial for meeting the modern requirements of professional standards, imposed by the society based on the recent studies on a teacher's role in early childhood education, child-rearing and development. The article is dedicated to providing a rationale for methodological approaches to developing teachers' communicative competence in the course of methodological work in preschool educational establishments, taking into account the personally-significant and professionally-oriented aspects. The main research technique used to study the problem is the method of participant observation. It made it possible to conduct an authentic evaluation, using the communication project method and analysis of the diagnostic study of 332 preschool teachers who took part in putting the concept of teachers' communicative competence development in the context of systematic employment in preschools into practice. The article shows how the applied pedagogical approaches, patterns and principles of the educational process, ensure the continuing compliance with the current requirements for teachers' level of professional training, particularly, the need for the constant development of communicative competence. The relevance of the problem is characterized by the qualitative changes in the composition of students of preschool educational establishments, constantly changing social situations, requiring prompt decision-making, aimed at ensuring the most comfortable, safe and progressive conditions for the younger generation. The article presents the results of the practical application of the proposed theoretical and methodological approaches, based on the pedagogical patterns and principles governing the development of teachers' communicative competence within the scope of preschool educational establishments. The result of the study is an elaborate set of methodological approaches, pedagogical patterns and principles working towards developing teachers' communicative competence at the general-theoretical, empirical and methodological-technological levels. The materials of the article can be of practical value for students and instructors of pedagogical and humanities universities, people in charge of curriculum and discipline at preschool educational establishments, whose job is to address the issues that preschool teachers face within the boundaries of continuing vocational education.
\end{abstract}

Keywords: Communicative competence; Methodological work; methodological approaches; pedagogical patterns; pedagogical principles; Teachers of preschool educational establishments.

\section{Introduction}

\subsection{Problem Relevance}

The socio-cultural changes that have become more and more widespread in Russia in recent years have led to a significant reevaluation of a teacher's place and role in the younger generation's upbringing, education and personal development. In contemporary society, teachers represent an important professional group, which has a significant impact on the society's culture, socio-political and economic processes. This is evident from the fact that an adult's (teacher's) role in raising a child is not limited to the transfer of knowledge from one generation to another which nowadays is one of the necessary conditions of bringing up the younger generation.

The relevance of this study is determined by the evolutionary trends in preschool education associated with the need to promote communicative competence among teachers, the lack of conceptual foundations for the system of teachers' communicative competence development that would reflect the dialectical unity of the theoretical and technological aspects of the process, inadequate prior research of the methodological and technological apparatus of the emerging concept.

Thus, the relevance of the study is based on the following contradictions:

- between society's growing need for professionally communicative individuals who use their communication skills as a means of interaction in various situations and spheres of life, and the established methodological practices prevalent in early education that are aimed at expanding the technological component of teachers' professional activity;

- between the growing importance of the true communicative culture of every member of society and strong negative tendencies in the development of the interpersonal interaction of the participants of the educational process;

- between the need to refocus the methodological work process within the early education framework on the practical mastery 
of cultural and speech norms of communication and sufficient didactic and methodological and technological support of this process in preschool education;

- between an objective demand for the scientific and methodological concept of teachers' communicative competence development at preschool educational establishments that reflects a unified system of communicative education at all career levels and the crude theoretical and methodological foundations in following the pedagogical principles of communicative education that the teachers adhere to in modern preschool education.

A scientifically-oriented solution to any problem requires a clear theoretical and methodological regulation, which is the most important attribute of any concept, because it determines the concept's nature, its content, its system of principles, as well as ways of organizing and arranging theoretical and practical activities. In light of this, the development of a set of theoretical and methodological approaches at the general-theoretical, empirical and methodological-technological levels, as well as formulation of pedagogical patterns and principles of preschool teachers' communicative competence development have become the most relevant issues $[1,2,3,4,5,6,7]$.

\subsection{Current State of Affairs in the Field of Communicative Competence Development among Preschool Teachers}

According to the Law of the Russian Federation "On Education", proceeding from the Professional Standard requirements "A teacher (teaching activities in preschool, primary general, basic general, secondary general education) (educator, teacher)" and from the main provisions of the federal state educational standard of preschool education, the requirements for continuing vocational training and personal development of preschool teachers have been undergoing changes. It is important to note the need for constant professional competence improvement of those teachers who are able to adapt to the new social and professional conditions, resolve problems and work as part of a team, are ready for overwork and stressful situations and know how to quickly overcome them, are capable of being flexible in terms of switching methods and educational life-forms on the basis of positive communication and social responsibility principles.

At the same time, there is now a clear discrepancy in the level of requirements laid down by the government with respect to the professional competence level of preschool teachers. On the one hand, there is a clearly expressed demand for building up relationships that are conducive to children's development, that promote open, trust-based, sustainable, and safe relations. On the other hand, there is a shortage of skilled professionals, lack of the necessary knowledge, system-wide orientation of professional training, retraining, development of vocational competence and methodological work within the early education framework towards mastering modern childrearing and educational technologies; a conflict between acknowledging a teacher's role as a subject of communication activity, which itself is a distinctive part of the professional occupation, and the absence of purposeful communicative competence development. Meanwhile, a lack of prior research into such assistance technologies for preschool teachers that would meet modern educational goals, train teachers to make full use of communicative space conducive to creating conditions for improving the quality of preschool education in general has been reported.

\subsection{Status of a Problem}

Preschool teachers are highly qualified professionals who have a sufficiently high professional and social status, who are able to learn and have high motivation for it: they train and participate in staff meetings, consiliums or conferences. They complete career enhancement training courses on a regular basis. For that reason, they do not perceive the learning process as a new challenge, rather as a continuation of the usual professional practices.

Teachers who undergo training are employees of the same preschool organization. Therefore, it is paramount to put in place the customized theoretical and methodological approaches to communicative competence development that will take into account the age and the professional and person-centred aspects. Approaches must be able to make allowances for idiosyncratic features related to the organizational, professional and psychological characteristics of every preschool teacher who attends the classes.

\subsection{Research Hypothesis}

Preschool teachers will be able to achieve high level of communicative competence development in the continuing education field if we implement a set of elaborate theoretical and methodological approaches in the methodological work of early education institutions, namely: the andragogical approach as the general scientific foundation, linguo-didactic approach as the empirical basis; tolerant-participative approach as the methodological and technological foundation of communicative competence development of preschool teachers. That said, in order to adequately explain the nature of communicative competence development of preschool teachers and allow for the theoretical and logical conclusions to be made with regards to all the provisions of this pedagogical concept, we believe it is necessary to highlight and examine the corresponding system of patterns and principles, which will allow us to solve a set of methodological problems, more specifically: address the fundamental intrinsic properties of communicative competence; disclose the possibility of determining interdependent factors affecting communicative competence development and its subsequent refinement; establish a connection between theory and practice of developing communicative competence of preschool teachers in the system of methodological work.

Over the course of the study, the following issues have been solved: 1) selection of experimental and control groups consisting of preschool teachers; 2) experimental groups training based on the proposed theoretical and methodological approaches, working with the control group on the basis of the traditional methods; 3 ) comparing the level of preschool teachers' communicative competence in both experimental and control groups; 4) experimental work outcome analysis, effectiveness assessment of communicative competence development of preschool teachers.

\section{Methodological Framework}

\subsection{Research Objectives}

It is important to develop and put into practice the methodology for preschool teachers' communicative competence development, whose philosophy and subject matter is associated with teachers' communicative competence development as a key component of both the professional and person-centred proficiency.

\subsection{Theoretical and Empirical Methods}

Hypothesis testing is achieved through the application of a set of diverse mutually supporting methods: theoretical (analysis of literature, regulatory, legislative, methodological, working papers and materials that deal with the research problem; research into and assimilation of innovative pedagogical experience, analysis, synthesis) and empirical (participant observation, summative and formative pedagogical assessment, questionnaire surveys, testing, interviews, conversations, as well as methods of mathematical statistics). 
Evaluation of the communicative competence development level was carried out using authentic assessment that relies heavily on the worked-out communication project, which is applied in practice-oriented education and makes provisions for appraising the learners' practical skills and knowledge (taken as a whole, the level of competence) in response to being placed in a real-life situation, both routine and professional.

\subsection{Study Base}

The study base was selected from amongst the Chelyabinsk city Teaching and Methodological Centre for Education Management, the preschool educational establishments in such cities as Zlatoust, Kurgan, Magnitogorsk, Miass, Ozersk, Orenburg, Orsk, Surgut, Snezhinsk, and Chelyabinsk.

\subsection{Study Phases}

The study was conducted in three stages.

The first stage is characterized by the research practice aimed at looking into and summarizing the characteristic features, keeping track of which in the methodological work process ensures teachers' communicative competence development in early education; in addition, pedagogical conditions (cognitive, contentrich, procedural, technological) necessary for successful fulfilment have been formulated.

During the second stage, the theoretical and methodological approaches to communicative competence development of preschool teachers have been cultivated and introduced into the real-world pedagogical practice, consistent with the selected pedagogical patterns and principles.

At the third stage, the results of the pedagogical experiment on communicative competence development of preschool teachers have been consolidated using the traditional approach and the proposed method, factoring in the implementation of all wellfounded pedagogical conditions.

\subsection{Evaluation Criteria}

Efficiency assessment with regards to the educational process was performed after observing how the preschool teachers coped with the situational tasks that approximated real-world conditions as realistically as possible using authentic assessment tools that rely on communication project development as an alternate attestation form that provides a comprehensive analysis of the various aspects of communicative competence. The results were processed using the mathematical statistics methods.

\subsection{Course and Description of the Study}

\subsubsection{Andragogical Approach as the General Scientific Research Foundation}

In order to determine the methodological requirements for the study of communicative competence development of preschool teachers, the methodology levels and their specific features were analysed. The general scientific level, encapsulating the general scientific concepts, implemented in the majority of the pedagogical studies, made it possible to investigate the given problem from the andragogical approach perspective.

Adoption of a two-level higher education system in Russia in accordance with the main provisions of the Bologna Declaration, transition from the generation of knowledge, skills and expertise to the competence implementation approach offers new perspectives to the young specialists working in the system of advanced training when it comes to the consideration of the modern approaches to devising the scientific foundations for teachers' professional competence development.
Andragogy is the science of adult learning, which provides feasibility for planning, implementing, evaluating and correcting the learning process for both students and educators $[8,9]$. Andragogy creates the theoretical and methodological foundations of the activities that help adults acquire the general professional knowledge, master cultural achievements and generate (or revise) life principles.

Implementation of the communicative competence development system of preschool teachers in this day and age is impossible without having a thorough understanding of the very core of the adult education system (Bim-Bad B.M., T.G. Brazhe, S.G. Vershlovsky, S.I. Zmeev, Z.N. Safina, A.P. Sitnik, G.S. Suhobskaya, E.P. Tonkonogaya, et al.).

Andragogy looks at education through the prism of a person's life path as a means of developing an ability to self-organize, selfregulate and self-actualize. The need for adult learning today is determined not only by the dynamics of social, scientific and technical progress but also changes in the content and the nature of labour and public activity and increase in free time and opportunities for its rational use.

For the sake of constructing a working theory that deals with adult learning, the andragogical approach is indispensable with its focus on integrity, consistency, and subject-to-subject interactions.

Analysis of the foreign and domestic literature showed great interest on the part of the scientists towards the andragogical approach. Yu.G. Fokin emphasizes that comprehension of the subject of education of his/her own needs, which can be satisfied in the sphere of education, and the necessity for a conscious effort to satisfy those needs is the main difference of the andragogical approach [10]. The scientific explorations done by Safina and Sheraizina disclose their collaborative work on the integrated synergetic-andragogical approach to the educational program design. Based on the formulation of the basic premises of the andragogical approach, the social and psychophysiological characteristics of an adult learner's attitude towards the learning process are presented [11].

In foreign education, the most well-known principles of the andragogical approach were developed by M. Sh. Knowles in the USA in the 20th century.

Traces of the comprehensive research into the andragogical approach are evident in the modern dissertation studies (Vozgova Z.V., A.I. Kukueva, L.V. Linevich, S.A. Filin, et al.).

Elaborating on the concept of communicative competence development of preschool teachers, we are guided by the recommendations of S.I. Zmeev, who highlighted the "five fundamental characteristics that distinguish an adult learner from the non-adult students: 1) he is aware of the fact that he has an independent, self-governing personality; 2) he accumulates a huge reserve of life (everyday, professional, social) experiences, which turns into an important source of motivation for both himself and his colleagues; 3 ) his readiness to learn (motivation) is determined by the desire to solve his real-life problems with the help of the educational activities and achieve specific goals; 4) he strives for the immediate implementation of the acquired knowledge, skills, expertise and qualities; 5) his educational activity is largely limited by the temporal, spatial, domestic, professional, and social factors (conditions)" [9].

Researching the general and individual components of adult learning separately has been the focus of the works of T.G. Brazhe S.G. Vershlovsky, A.V. Darinsky, V.Yu. Krichevsky, A.E. Maron, A.Yu. Panasyuka, G.S. Sukhobskaya, E.P. Tonkonoy, P.V. Khudominsky, and others.

Definition of the andragogy given by S.I. Zmeev [9] allows us to speculate that the andragogy views learning in the context of a person's life path as a means of developing the person's ability to self-organize, self-regulate, and self-actualize. The key to the professional success no longer lies in the knowledge gained only once in a lifetime. The adult's ability to navigate in a huge infosphere, to independently find solutions and implement them successfully comes to the forefront. When considering the 
problem under study that deals with the impact the pedagogical concept has on communicative competence development of preschool teachers, it is impossible to build an effective system of methodological work in early education without taking into account the specifics of adult learning. Our research supports the assumption that for a teacher working with preschool children knowledge alone is not enough, opportunities for solving vital problems with the goal to promote self-affirmation and selfrealization are the key. Knowledge per se is just one of the conditions for successful problem-solving. In other words, the process of acquiring new knowledge is crucial, but so is the continuing communicative competence development, which includes the following components: knowledge in the field of communication studies; communicative and organizational abilities; capacity for tolerance and empathy; self-control; and prevalence of verbal and non-verbal interactions.

It is possible to earmark the following key characteristics of the andragogical approach as the general scientific foundation of the pedagogical concept behind communicative competence development of preschool teachers:

- concept orientation of communicative competence development of preschool teachers towards establishing the correlation between the level of teachers' readiness to implement the challenges of preschool education, determined by historical, political and socio-economic necessity, and giving a person an opportunity to "be himself/herself", be achievement-oriented;

- organization of methodological work in preschool educational establishments on the basis of age, psychophysical and personal characteristics as well as professional competencies, in accordance with the needs and life experiences of preschool teachers;

- ensuring, in the process of developing preschool teachers' communicative competence, their own interest in the educational service - understanding that their own problems can be solved by means of the educational process;

- organization of preschool teachers' communicative competence development process in the system of methodological work in early education with systematic monitoring of the development level of teachers' awareness of goals, subject matter, structure, means, and features of the pedagogical communication; proficiency level when it comes to relevant technology; specialists' personal psychological qualities; aspiration towards constant improvement of communicative activity; focus on a person's personality as the core value, and propensity for outof-the-box, creative problem-solving, arising in the course of the pedagogical dialogue;

- application of the educational technologies that ensure integrity, consistency, and subject-to-subject relations in the process of communicative competence development of preschool teachers.

\subsubsection{Linguo-didactic approach as the empirical foundation}

Empirical research methodology is presented in the form of the linguo-didactic approach. The linguo-didactic approach is premised on the systemic position of language with its function as an intrinsic human property in the pedagogical activity, which underlies the development of spirituality, intellect and cultural identification of a learner [12].

A significant contribution to the linguo-didactic approach development was made by G.I. Bogin, L.I. Bozovic, N.D. Galskova, I.A. Zimnyaya, L.F. Minyar-Beloruchev, N.M. Shansky, and others. For instance, N.M. Shansky believed that linguodidactics examines the common denominators as far as teaching languages is concerned, formulated the general principles relating to the ways of internalizing foreign knowledge, skills and practices. L.F. Minyar-Beloruchev regarded linguo-didactics as a science, which includes the theoretical and practical methods of teaching languages. However, he believed that the main objective of linguo-didactics lies in developing the teaching language methodology, making sure that it introduces the subject of instruction in its direct connection with the nature of language and the nature of communication, in which the pragmatist essence of the speech content is manifested. G.I. Bogin supposed that linguodidactics examines the mastery patterns of any language, regardless of whether the language in question is the first one or the second [13].

Basically, all contemporary researchers believe that, broadly speaking, linguo-didactics, along with other scientific fields (psychology, psycholinguistics, linguistics, didactics, etc.) is designed to develop the basics of language instruction, while falling back on the comprehensive integrative foundation, while the teaching language methodology and other teaching techniques solve specific problems, associated with a specific language and specific learning conditions.

For our study, it is important to consider the way linguo-didactics interacts with a number of scientific disciplines associated with the language teaching and being considered basic for the study of communicative competence of preschool teachers. Among them linguistics, psychology, sociology, linguoculturology, didactics, and communication theory.

Linguistics is the fundamental component of the scientific disciplines lying at the heart of language teaching. In its current state, linguistics is characterized by a wide variety of subjects and research units. Its main subjects, aside from language, include speech, oral activities, speech subject, speech behaviour, and actual formation processes of the spoken message and its assimilation; conditions in which they run their course, and much more. In point of fact, the individual didactics methodology is being transformed into linguo-didactics, given that such a variety of subjects of linguistic examination is included in the methodology as well.

The influence of psychology on the state of the linguo-didactic theory is of great significance. Speech psychology examines oral and written, external and internal speech, various aspects of speech activity, speech subject; pedagogical psychology refers to how knowledge, skills, and practices come into existence, how higher mental functions are applied in the learning process; general psychology covers motivational sphere of activity of a speech subject (I.A. Zimnyaya); problems of speech and cognition (Vygotsky L.S., A.R. Luria, \& A.N. Leontiev); social psychology examines the speech behaviour of different social groups, language standards or norms, socio-cultural aspects of communicative competence, understanding as the socio-cultural process; cognitive psychology draws close attention to linguodidactics, while focusing mostly on the cognitive processes.

In general, contemporary linguo-didactics is a psychological field of scientific knowledge. At the same time, it is essential to consider the problems and state of the scientific thought in relation to a person as an individual, as an active participant and as a subject of social life.

In the 1960s of the XX century, linguoculturology, which "works collaboratively" with linguo-didactics, had emerged at the junction of linguistics and the disciplines of culturological orientation. Linguoculturology studies the interrelation and interaction of culture and language, which creates distinctiveness of the national language outlook. The study of language as a system, in which cultural values find their evocation, is of particular interest. Linguistics has long established an understanding of communication as the exchange of information, carried out in the process of socializing.

Communicativeness presupposes such an organization and orientation of language classes, where "the education goal is connected with ensuring the maximum approximation of the learning process to the actual process of communication in the studied language in all or several types of speech activities and various spheres of communication (everyday, educational, professional, socio-cultural)" [12]. The developed teaching materials and training classes for preschool teachers are aimed at developing teachers' ability to use their knowledge and skills in the natural communications, interacting with various categories of 
preschool children. The learning process is characterized as a personal interaction, where different methods of communication are used. Cooperation in communication ensures the preservation of the high level of motivation when it comes to learning. We share the opinion that the specified approaches to linguodidactics actualize the system-forming role of language as the bearer of culture, spirituality and intellect. The most important constructs of communicative competence development of preschool teachers in the context of the linguo-didactic approach are:

- the goal is the formation of preschool teachers' communicative competence (changing the tasks of the educational process in the early education framework of methodological work towards actualizing productive communication created on a parity basis and interpersonal communication; formation of personality capable of interacting with children, taking into account their age and psychophysical features in different life situations);

- content that includes such components as communicativebehavioural, person-oriented, linguocultural.

That said, the communicative and behavioural components of preschool teachers' communicative competence content include the linguistic and verbal knowledge, skills and practices, as well as the implementation of diverse teaching materials, which are represented by the communicative, interactive and linguistic aspects in the methodological work system of early education.

Person-centred component is reflected in various kinds of materials and addresses the specialist as a person, an individual, defining his/her attitude towards himself/herself, people around $\mathrm{him} / \mathrm{her}$, and pattern of the children's culture. Specifically, it should be noted that a teacher mobilizes his/her subjective experiences and personal potential for the sake of achieving his/her personal goals.

The linguocultural content component of preschool teachers communicative competence is directed at the development of such intellectual operations as comparison, expansion of the cognitive awareness of the educators around the world and the inner world of a preschool child. Through this component, it becomes possible to acquaint the teachers with cultural creations using the language within the professional development system. Thus, the linguocultural component promotes the sense of tolerance, encourages interaction and mutual understanding between the partners during communication, mastering of communication techniques and speech etiquette, so that in the future they can be used in the real-world situations not only with different categories of preschool children but also with all the participants of the educational process.

The specific nature of applying linguo-didactic approach to the development of preschool teachers' communicative competence lies in the fact that:

- language acquisition is not only a means of communication, but also a means of obtaining a variety of information relevant to the main activities of preschool teachers;

- language training is carried out with an eye towards the integration of various areas of pedagogical specialty;

- language training is aimed at the formation of, mainly, practical skills;

- an expansion of preschool teachers' linguistic world image can be observed;

- professional technological competence of preschool teachers perfects itself (awareness of goals, content and means of preschool linguo-didactics).

\subsubsection{Tolerant-Participative Approach as the Methodologica and Technological Research Foundation}

The tolerant-participative approach in our study constitutes the methodological and technological foundation.

The methodological and technological level describes the methods and procedure for establishing interaction between all entities that are in open and equal relationships in order to achieve the predicted final result. The characteristics presented at these levels of methodology allow us to speak about their deep internal unity, interconnection, congruence, and complementarity, as well as an abundance of ideas that are productive in terms of optimal problem-solving when engaged in the pedagogical activities. This approach to the research problem, its comprehension from different points of view made it possible to choose not one but a synthesis of several previously known theoretical and methodological approaches. Analysis of the scientific literature, consolidation of the pedagogical experience, and our own experimental data make it possible to say that the solution to the indicated scientific problem can be successfully realized if the tolerant-participative approach is used as the basis for the methodological and technological foundation of communicative competence development of preschool teachers.

The theoretical and experimental research results showed that unconditional acceptance, non-evalutiativity, congruence, empathy, understanding, involvement, interest are the terms of the new tolerant-participative approach as the methodological and technological foundation for the study of communicative competence of preschool teachers.

Analysis of the scientific literature has shown that the term "participativity" refers to such concepts as "participation", "complicity", and "involvement", while the term "tolerance" signifies "toleration", "patience", "flexibility", "benevolence", and "acceptance".

In a broad sense, "tolerance" means toleration of other people's opinions and actions, ability to treat them without irritation. A tolerant person respects convictions of others, without trying to prove his/her superior right.

The socio-cultural meaning of tolerance is thought of as a certain quality of interpersonal relations and groups, as well as individual persons. It is characterized by a set of favourable attitudes towards "others", a desire not only to understand but also to accept, as much as possible, their traditions, culture, convictions, beliefs, interests and values. In the pedagogical studies, the approaches to tolerance are often integrated. A.G. Asmolov views tolerance as resistance to conflicts, willingness to engage in dialogue with a person who causes negative reaction [14]

S.K. Bondyreva describes tolerance as the ability of an individual to perceive opinions, way of life, behaviour patterns, etc. different from one's own without objection and opposition. L.B. Kordakova conducts an in-depth analysis of the pedagogical tolerance as the important quality of any teacher. A.V. Kandaurova and M.N. Labikova emphasize the role of a teacher's tolerance in social interactions. Tolerance in the field of professional activity has been considered in relation to a teacher's personality as a subject of frustration tolerance [15].

Tolerance, being a multidimensional phenomenon, has become the subject of profound interest in professional pedagogy. After analysing the characteristic features of a teacher's tolerance, Yu.P. Povarenkov identified two types of the said phenomenon in the pedagogical process: social (or socio-psychological) and psychological (or psychophysiological) [16]. The presence of social tolerance allows a teacher to interact effectively with all participants of the educational process, and the formation of psychological tolerance ensures one's resistance to numerous professional stresses and promotes effective career building.

It becomes obvious that tolerance is a special moral quality that encapsulates a pro-active social position and psychological readiness for positive interaction with people or groups of other national, religious, and social backgrounds, other views, mindsets, lines of thought and behaviours.

Let us present the basic definitions of the word "tolerance" "acceptance of other interests and goals that differ from your own"; "friendliness, calmness, peaceful disposition, the opposite of aggressiveness, spitefulness, irritability"; "ability to listen, isolate the seed of reason from the information received and get along with different points of view, whether it contradicts one's own views or not"; "desire for harmony, lack of conflict", which 
are an important condition for improving the quality of preschool education.

Based on the data of contemporary science, as well as the results obtained during the consolidation and analysis of the existing experience, it is important to identify the main functions of tolerance:

- Regulatory - allows to contain hostility in combination with a postponed positive reaction, or replace it with a positive one; provides a constructive way out of conflict situations; focuses relationships on adherence to the principles of equality, respect, and freedom;

- psychological - serves as the foundation for normalizing psychological atmosphere in a group of preschool children (atmosphere of trust, respect, recognition, support); forms and develops ethnic self-awareness; promotes ethnic and social selfidentification; maintains and contributes to personal and groupwide self-esteem; reduces the sensitivity threshold to unfavourable factors, frustrating situations;

- educational - secures the transfer of positive social interaction and human experience as a whole; provides the perfect example of the organization of daily-living activities in society; ensures successful socialization; develops moral understanding, empathy, ability to assess actions of others in a non-judgemental way;

- communicative - develops readiness for communication, cooperation, understanding; allows establishing constructive communication with the representatives of different groups, of a different outlook.

Outlining certain qualities in a teacher that characterize him/her as tolerant is of particular importance. G.A. Lopushnian tentatively separates three groups: 1) qualities that characterize a teacher's attitude towards himself/herself as inherently valued (selfacceptance, self-control, self-esteem, self-control, selfdetermination, self-actualization, self-criticism, self-education, self-assertion, display of inner strength in a decision-making situation, self-reflection, etc.); 2) qualities that characterize a teacher's attitudes toward others as worthwhile (desire to work together with others, inclination towards other people, ability to listen to one's companion, acceptance of others, benevolence, etc.); 3) qualities manifested in communicative situations (restraint, profound patience, endurance, forbearance, compassion, empathy, readiness to create new values, flexibility, etc.) [17]. In addition, in his studies, G.A. Lopushnyan considers a teacher's tolerance model, which includes a description of the tolerant personality traits in seven spheres of the psyche: intellectual, motivational, volitional, emotional, subject-oriented and practical, and existential spheres as well as the spheres of self-regulation [17].

The idea that tolerance is not an inborn quality, but instead can be shaped and developed not only throughout the entire professional career but in life in general provides the majority of the researchers (Adzhieva E.M, Yu.P. Povarenkov, \& O.V. Rubtsova) with an insight into the ground-breaking new solutions to the problem $[16,18,19]$.

Consequently, tolerance is seen not only as a personally significant quality but also as an absolute necessity in the pedagogical career in general and in the system of early childhood education and learning in particular. It is in the pedagogical professional environment that acceptance of each participant of the educational process is introduced as an indispensable condition for the effectiveness of the process of education and upbringing when all the participants are be able to maintain mental and psychological health, develop their creativity, and show human dignity.

The participative approach was first introduced by E.Yu. Nikitina in the theory and methodology of vocational education with respect to the prospective teachers' training in the field of management of educational differentiation [20]. In our opinion, the term "participativity" is the most accurate and complete in the semantic sense. At the same time, we consider this category as an alternative to authoritativeness, directiveness, coercion.

Participativity implies interaction (and not influence) between teachers and all participants in the communicative situation with the purpose of developing and implementing a joint solution to the communicative situation, which is subject-to-subject. In this regard, the mechanism of such interaction should resemble negotiations with a view towards finding common ground with respect to the problem of making a single coordinated decision and ensuring activity.

Based on the above-mentioned, participation in communicative competence development of preschool teachers entails:

- opinion of each participant in the communicative situation when solving a particular communicative situation problem;

- consultations, looking for common ground between the communicative situation participants and a teacher;

- purposeful, systematic attempts to identify and use individual and collective wisdom of all trainees;

- joint decision-making;

- joint problem identification and related actions, opportunity to create suitable conditions and facilities, as well as the mechanism for improving cooperation between a teacher and students.

Summarizing the above-mentioned, let us name the characteristic features inherent in the tolerant-participative approach:

- acceptance of a child's individual characteristics;

- consideration of a child's opinion when resolving serious communicative problems;

- joint decision-making on part of a teacher and a preschooler;

- dialogical interaction between a teacher and a preschooler, based on the principles of tolerance;

- reaching consensus when solving communicative problems;

- voluntary involvement and interest of all participants in the educational process;

- participants' communicative competence in the educational process.

Consequently, implementation of the tolerant-participative approach to communicative competence development of preschool teachers allows them to cultivate the qualities that will help them withstand the hardships of the educational process and get used to them in the process.

Summarizing the analysis outcomes of the methodological forecasting of preschool teachers' communicative competence development concept, it can be noted that it provides the foundation for its sound development.

\subsubsection{Pedagogical Patterns and Principles of Communicative Competence Development}

The concept of communicative competence development of preschool teachers within the methodological work system is a complex, purposeful, dynamic system of fundamental knowledge of the individual communication phenomenon in early education, which fully and comprehensively reveals its essence, content, features, and operating technology in the context of modern preschool education.

Consequently, the patterns and principles of the studied pedagogical phenomenon that make it possible to explain the essence of preschool teachers' communicative competence development and provide an opportunity for the theoretical and logical conclusion of all the provisions of the pedagogical concept have proved to be the central component of the pedagogical concept. Regularity is an objectively existing, repetitive, substantial link between the social life phenomena or "stages of historical development" [21]. A logical continuation of the concept formulation of communicative competence development of preschool teachers is the isolation of the relevant principles as the most important, basic components of the theoretical knowledge. A principle is something that should guide an active participant in his endeavours. 
The analysis of the scientific research has shown that principles are the basic, original starting points of any theory, doctrine, worldview, theoretical program, conviction, view of life [22, 23]. The comprehensive analysis of the content and structure of early education in general and professional activities of preschool teachers in particular, scientific and methodological literature, regulatory and legal documents and our own scientific, methodological and experimental work allowed us to single out the pedagogical patterns of communicative competence development of preschool teachers and the corresponding principles:

1) deterministic patterns (reflect the factors that determine the phenomenon being studied):

- development of communicative competence is based on having an adequate grasp of the profession and the socio-practical significance of the professionally important qualities as a system that determines this competence. This indirectly determines a teacher's self-esteem and self-reflection that develop in the course of one's career (the principles of polysubjectivity, all-round personal development, empathy);

- development of communicative competence is not seen as an object of transfer of certain information, which is accompanied by a set of actions, but as an object of understanding and assimilation manifested in the possibility of activating said knowledge, skills, practices, personal qualities and behavioural attitudes, primed to the conditions of the specific interaction situation and readiness to use them in action, which determines the nature of competence (principles of adaptability, communicative partnership and cooperation);

- development of communicative competence is based on a teacher's own actions and is intricately connected with the system-coherent motivation that unites cognitive needs, interests, passions, emotions, attitudes and ideals of each teacher, striving to know themselves and others in the process of communication, accept various forms of self-expression, be able to transform the situation (principles of synergy, facilitation, vital experience actualization).

2) attributive patterns (reveal the intrinsic characteristic features and properties of the phenomenon being studied):

- communicative competence allows a preschool teacher to get the language of communication consciously, which presupposes the teacher's understanding of the linguistic material in the unity of its functions, language means of communication in the unity of their forms and content (principles of abiding by the linguistic and conventional norms of the communicants' speech behaviour, dialogueness, orientation);

- development of communicative competence has the communicative orientation, which requires the use of language as the means of communication, preschool teachers being able to achieve the defined pedagogical communication level (principles of linguistic tolerance, linguoculturology, polyculture).

3) productive patterns (reveal the circumstances of effective functioning of the phenomenon being studied):

- process of development of communicative competence is conducted on the basis of specific pedagogical model creation with a specified volume of knowledge, skills, practices, and work methods relating to preschool teachers' communicative competence (principles of variability, structural completeness, cyclical development);

- development of communicative competence of preschool teachers is a continuous process of an integral methodological system functioning, that is based on the dynamics of the stepby-step expansion of the volume of the acquired communicative knowledge, skills and practices (principles of continuity and reflexivity);

effectiveness of the process of developing communicative competence of preschool teachers depends on the creation and implementation of the methodological system that integrates diverse possibilities of communicative activity (principles of consistency and succession, orientation of learning towards solving problems in the professional sphere).

\section{Results}

\subsection{Pedagogical Conditions Conducive For Optimal Goal Fulfilment}

Conducting the theoretical research and practical pedagogical activity allowed us to determine the teaching conditions that ensure the practical implementation of the above-mentioned theoretical approaches at all levels. Let us point out the organizational and pedagogical conditions (cognitive, content-rich, procedural, technological), that are, from our point of view, most conducive to the successful achievement of the stated goal teachers' communicative competence development in the process of early education methodological work:

Cognitive and content-rich conditions:

- formation and development of tolerant-empathic communication values among the preschool teachers;

- development of the circular structure of the teachers' knowledge, understanding and internalizing information;

- preschool teachers' orientation towards awareness, acceptance of and abidance by the principles of pedagogical correctness and linguistic tactfulness;

- the process of enriching the teachers' media culture.

Procedural and technological conditions:

- implementation of strategic and tactical technologies for the development of communicative competence of preschool teachers;

- inclusion of professionally and person-centred information;

- encoding and decoding of linguistic scientific information;

- accounting for the specifics and diversity of various discourse types;

- authentic assessment based on the communication project development as an alternate way of assessing the communicative competence of preschool teachers.

\subsection{Experiment Progress and Results}

To confirm the effectiveness of the developed approaches, pedagogical patterns and principles, experimental work has been carried out that allows us to mathematically substantiate the identified trends and test the effectiveness of the set of proposed pedagogical methods for developing the communicative competence of preschool teachers in the early education methodological work system.

The formulated goal determined the nature of the key tasks that we set to solve in the course of our experimental work:

- determine the level of communicative competence of preschool teachers prior to the start of training and in the event of teaching relying on traditional methods;

- develop programs for diagnosing communicative competence of preschool teachers in the methodological work system, taking into account the modern professional standard's requirements;

- select and substantiate the sample representativeness and statistical criteria that evaluate the research results;

- assess the significance and direction of the changes that occur in the learning process;

- identify the most significant factors affecting the process of communicative competence of preschool teachers.

While being part of the experimental work, preschool teachers were conveniently divided into two groups: control (CG - 168 people) and experimental (EG - 164 people).

During the first stage, through testing, the initial level of communicative competence of preschool teachers was revealed. The compared characteristics of communicative competence 
formation level showed that preschool teachers, assigned to either experimental or control group, had an identical level of communicative competence development.

A number of preschool teachers that showed insufficient levels of communicative competence was as follows: in the CG $-38.69 \%$, in the EG - 35.98\%; moderate level: in the CG - $60.71 \%$, in the EG - $62.80 \%$; high level: in the $\mathrm{CG}-0.6 \%$, in the $\mathrm{EG}-1.22 \%$, The obtained results revealed real problems in the field of communicative competence in the context of preschool educational establishments. The statistical evaluation that was carried out confirmed the significance of the obtained results and the homogeneity of the initial experimental conditions.

After having preschool teachers trained in the system of methodological work, the following results were obtained. The CG implemented training using the traditional methods, the EG used the approaches described above. After the end of the training, the number of preschool teachers that demonstrated insufficient levels of communicative competence was: in the CG - $13.09 \%$, in the EG - 1.22\%; those who showed moderate levels of communicative competence: in the CG - 83.93\%, in the EG $26.22 \%$; those who showed high levels: in the CG $-2.98 \%$, in the EG $-72.56 \%$. Figure 1 shows the results prior to and after the experiment.

Prior to the

Experiment

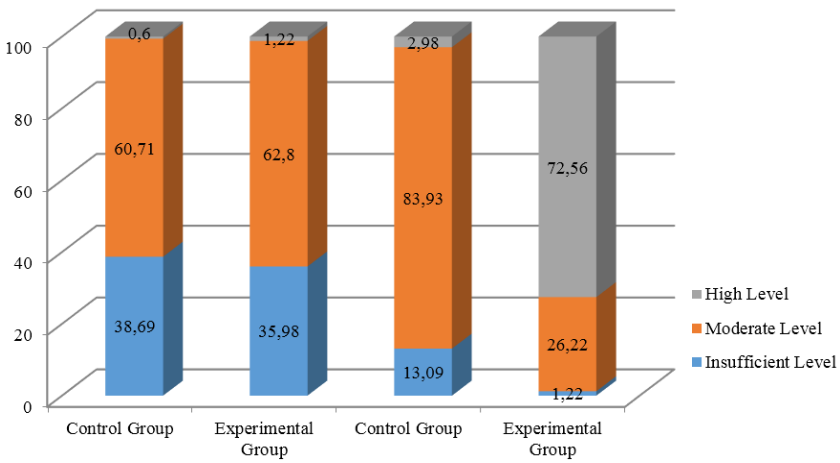

Fig. 1: Correlation between the Levels of Developed Communicative Competence in the CG and the EG Prior to and After the Experiment

The results of testing, polling, observations and deductions served as the sources of primary input data, based on the preschool teachers discussion results dealing with the tasks that reflected real-life situations associated with the application (manifestation) of communicative competence with the purpose of solving communicative problems and finding adequate solutions in interaction situations between the participants of the educational process.

The results of the experimental study testify to the effectiveness of the theoretical approaches, pedagogical patterns and principles described in the pedagogical practice, and confirm the relevance of this study.

\section{Discussion}

The main prerequisites for the development of communicative competence of preschool teachers are the social, economic and technological changes that currently take place. High level of education and specificity of teachers' professional activity requires special methodological approaches to be applied to the design of all methodological work in early education.

In this experiment, a comparison was made between the formation levels of the two groups of preschool teachers. The study showed a significant increase in the controlled variables among the preschool teachers of the experimental group as opposed to the preschool teachers of the control group who were trained in accordance with the traditional method.

\section{Conclusion}

The proposed interpretation of the andragogical approach as a general scientific principle, the linguo-didactic approach as an empirical foundation and the tolerant-participative approach as the methodological and technological foundation of the methodology of teachers' communicative competence development that allows us to consider the methodological work in the early education setting in terms of its inclusion in the process of continuing improvement of the teachers' professional skills, while taking into account the contemporary pedagogical requirements and development tendencies of the society.

\section{Recommendations}

The results of the research described in the article will be extremely useful to both students and instructors of pedagogical and humanities universities, people in charge of curriculum and discipline at preschool educational establishments that are meant to solve issues that preschool teachers have to deal with in the context of continuing vocational education.

\section{References}

[1] Vasilyeva VS (2011), Andragogical Approach as A Community Basis of The Pedagogical Concept of Development of The Communicative Competence of Teachers of Preschool Education. International Journal of Experimental Education, 10, 119-122.

[2] Vasilyeva VS (2015), Methodological Bases of Pedagogical Concept of Development of Communicative Competence of Teachers of Preschool Educational Establishments. International Journal of Applied and Fundamental Research, 2, 13.

[3] Vasilyeva VS (2011), Methodological Approaches to Communicative Competence Development of Preschool Teachers. Contemporary Problems of Science and Education, 3, 30.

[4] Vasilyeva VS (2016), Scientific and Theoretical Foundations of the Concept of Competence Development of Teachers of Preschool Educational Establishments. International Scientific and Research Journal, 11-3(53), 27-29.

[5] Vasilyeva VS (2015), Theoretical and Pedagogical Aspects of Formation of Communicative Competence of Teachers of Preschool Educational Establishments. Science, Education, Society, 4(6), 80-94.

[6] Vasilieva VS (2010), Tolerant-Participative Approach as Methodological and Technological Foundation for Communicative Competence Development of Teachers of Preschool Educational Establishments. Bulletin of Chelyabinsk State Pedagogical University, 12, 28-36.

[7] Vasilyeva VS \& Nikitina EYu (2017), Theoretical and Methodological Foundations of Communicative Competence Development of Teachers of Preschool Educational Establishments. Moscow.

[8] Zmeev SI (2007), Andragogy: Fundamentals of Theory, History and Technology of Adult Learning. Moscow: PER SE.

[9] Zmeev SI (2002), Technology of Adult Learning: Textbook for Students of Higher Educational Institutions. Moscow: Akademiya.

[10] Fokin YuG (2002), Teaching and Child-Rearing in Higher Education: Methodology, Goals and Content, Creativity. Moscow: Akademiya.

[11] Safina ZN (2005), Innovative Trends in the Development of Regional System of Adult Learning: Dissertation. Novgorod.

[12] Vorozhtsova IB (2007), Fundamentals of Linguo-Didactics. Textbook for Students of Higher Educational Institutions with a Major in Philology. Theory and Methods of Teaching Foreign Languages and Literatures. Izhevsk: Udmurt State University.

[13] Bogin GI (1981), Contemporary Linguo-Didactics. Kalinin: KSU Publishing House.

[14] Asmolov AG (2002), Personality Psychology: Principles of General Psychological Analysis. Moscow: Smysl, Akademiya.

[15] Mitina LM (1994), Teacher as an Individual and a Professional. Moscow: Prosveshcheniye.

[16] Povarenkov YuP (2003), Psychological Characteristics of the Teacher's Professional Tolerance. Issues of Psychology of 
Attention: A Collection of Scientific Works. Saratov: University’s Publishing House Sarat, 21.

[17] Lopushnyan GA (2010), Model of the Teacher's Tolerance in Light of the Concept of Individuality. ChGPU Herald 1, 128-134.

[18] Adzhieva EM (2003), Pedagogical Approaches to Tolerance Education. In: Tolerant Consciousness and Formation of Tolerant Relationships (Theory and Practice): A Collection of Scientific and Methodological Articles. Moscow: MPSI; Voronezh: NGO "MODEC", 216-223.

[19] Rubtsova OV (2009), Tolerance is a Necessity Dictated by Time. Novoe pokolenie: uchimsya vmeste. Kopeisk, 58-62

[20] Nikitina EYu (2000), Theoretical and Methodological Approaches to the Problem of Preparing a Future Teacher for Working in the Field of Management of Educational Differentiation. Chelyabinsk: ChPGU Publishing House, 2000.

[21] Belkin AS \& Verbitskaya NO (2007), Vitagenic Education in the System of Pedagogical Knowledge (Vitagenic Concept of Personality). Pedagogical Education in Russia, 1, 26-32.

[22] Efremova TF (2005), The Most Complete Modern Explanatory Dictionary of the Russian Ranguage in 3 Volumes. Moscow: ACT

[23] Ozhegov SI \& Shvedova NYu (2010), Dictionary of the Russian Language. Moscow: Onyx. 